\section{Reliability of FEA on the Results of Mechanical Properties of Materials}

Erica Alves Gomes ${ }^{1}$, Hugo Henrique Diana ${ }^{1}$, Juliana Santos Oliveira', Yara Teresinha

Corrêa Silva-Sousa ${ }^{1}$, Adriana Cláudia Lapria Faria², Ricardo Faria Ribeiro ${ }^{2}$

The present study evaluated the reliability of FEA on the results of different mechanical properties ( $\mathrm{E}$ and $\mathrm{v}$ ) of materials. Two 3D models of a maxillary canine with endodontic treatment, intracanal post, composite resin core and restored with porcelain-fused-tometal crown were generated according to micro-CT images. Two groups with different E and $v$ values for porcelain, metal coping alloy, resin cement and composite resin were established. The materials' properties for group GL were based on literature data, while for group GIE the impulse excitation technique was used. A load of $180 \mathrm{~N}$ was applied at $45^{\circ}$ on the incisal third of the lingual surface of the canine tooth. All models were supported by the periodontal ligament $(x=y=z=0)$. The von Mises stress (VMS) was calculated. The stress values revealed differences between the groups for both VMS distribution and value. The porcelain (GL: $5.966 \mathrm{MPa}$; GIE: $7.478 \mathrm{MPa}$ ), metal coping (GL: $3.811 \mathrm{MPa}$; GIE: $0.973 \mathrm{MPa}$ ) and core (GL: $4.771 \mathrm{MPa}$; GIE: $0.026 \mathrm{MPa}$ ) were significantly affected. In conclusion, this study showed that the determination of mechanical properties ( $E$ and $v$ ) of materials is essential for the reliability on the results of FEA.
'Dental School, UNAERP -

Universidade de Ribeirão Preto, Ribeirão Preto, SP, Brazil

${ }^{2}$ Department of Dental Materials and Prosthodontics, School of Dentistry of Ribeirão Preto, USP - Universidade de São Paulo, Ribeirão Preto, SP, Brazil

Correspondence: Profa. Dra. Erica Alves Gomes, Av. Costábile Romano, 2.201, 14096-900 Ribeirão Preto, SP, Brasil. Tel: + 55-16-3603-7000. e-mail: ericaagomes@yahoo.com.br

Key Words: finite element analysis, mechanical properties, research.

\section{Introduction}

Finite element analysis (FEA) has been suggested as an efficient method to simulate a real clinical scenario and solve complex problems by evaluations of inner structural performance $(1,2)$. Thus, it has also been considered as an important method to foresee long-term failures (3).

FEA is a computational analysis that transforms a physical problem into a virtual model that presents mathematical equations to the finite element software. The virtual model containing several structures with specific mechanical properties is divided into small fragments to generate the finite element mesh (4). As result, the performance of materials, techniques, displacement and stress distribution under load are numerically simulated in the model (5).

The method is considered as a fast and low-cost technique that does not require a large sample size and avoids human-related failures $(6,7)$. Conversely, the reliability of results obtained by numeric methods should be carefully interpreted because it depends on the accurate simulation of the structure's geometry, mechanical properties of the materials, interface, support and load (8).

Young modulus (E) and Poisson ratio ( $v$ ) of each simulated structure are the main mechanical properties to be used in static FEA. In general, the properties suggested by the literature are usually applied in the studies since complex and time-consuming laboratorial techniques are required to establish those values (9). Thus, most FEA studies are based on mechanical properties of materials with specific composition and unknown brand, which may influence the results of the research.
Dynamic impulse excitation technique $(10,11)$ has been indicated to determine the mechanical properties of the materials since it determines the Young modulus and Poisson ratio of different materials by using nondestructive approaches. Although the pulse-echo ultrasound method is also suitable to determine $E$ and $v(10,11)$, it is a high cost not commonly used alternative.

The aim of this study was to evaluate the reliability of FEA on the results of different mechanical properties ( $E$ and $v$ ) of materials, using literature data and the impulse excitation technique. The work hypothesis assumed no difference in stress value and distribution between the models.

\section{Material and Methods}

\section{Finite Element Model}

Micro computed tomography (micro-CT) slices (SkyScan $1174 \mathrm{v} 2$; Bruker-microCT, Kontich, Belgium) were used to determine the 3D geometry of a maxillary human canine. The 3D model was generated using the Simpleware 4.1 software (Simpleware Ltd, Exeter, UK) and micro-CT images. All simulated structures (enamel, dentin, pulp and periodontal ligament) were included in the solid model and the 0.2-mm-thick periodontal ligament was designed by Boolean operations (12).

According to a previous study (13), the following scenarios were simulated with CAD structures (SolidWorks Corp., Concord, MA, USA): (i) endodontic treatment with $14 \mathrm{~mm}$ working length; (ii) intracanal restoration with a prefabricated parallel sided fiber post (14 $\mathrm{mm}$ long and $1.5 \mathrm{~mm}$ diameter), preserving $4 \mathrm{~mm}$ of gutta-percha at the apical region; (iii) $50-\mu m$-thick cementation line ; 
(iv) composite resin core to restore crown structure and simulated tooth preparation with $1 \mathrm{~mm}$ reduction in buccal and lingual surfaces and $2 \mathrm{~mm}$ in the incisal edge; (v) prosthetic restoration with a porcelain-fused-to-metal crown using a metal coping $(0.5 \mathrm{~mm}$ thick and $0.5 \mathrm{~mm}$ porcelain) in the buccal and lingual surfaces and $1.5 \mathrm{~mm}$ on the incisal edge. The CAD images were transferred to the Simpleware 4.1 to create the 3D model.

\section{Properties of Materials}

Two groups were created with different mechanical property values of the materials (Young modulus [E] and Poisson ratio $[v]): G L$ - mechanical properties of all materials were based on literature data (Table 1); and GIE - mechanical properties of resin cement, composite resin core, metal coping and porcelain were determined by the impulse excitation technique while the properties of the remaining materials were similar to GL (Table 2).

Sonelastic (ATCP Physical Engineering, Ribeirão Preto, SP, Brazil) equipment was used to determine the mechanical properties of the materials using the impulse excitation technique. Three samples $(4 \mathrm{~mm}$ wide, $2 \mathrm{~mm}$ high and $25 \mathrm{~mm}$ long) were fabricated for each material: ¿ 1 - porcelain (IPS InLine PoM, Ivoclar Vivadent AG, Schaan, Liechtenstein), 2 - resin cement (Rely X, 3M/ESPE, St Paul,

Table 1. Mechanical properties of the group GL materials

\begin{tabular}{lccc}
\hline Material & E (GPa) & $v$ & Reference \\
\hline Porcelain & 69 & 0.3 & 14 \\
Resin cement & 18.6 & 0.28 & 14 \\
Metal coping & 92 & 0.33 & 15 \\
Composite resin core & 12 & 0.30 & 16 \\
Dentin & 18.6 & 0.31 & 17 \\
Periodontal ligament & $6.89 \times 10^{-5}$ & 0.45 & 17 \\
Gutta-percha & $1.4 \times 10^{-1}$ & 0.45 & 18 \\
\hline
\end{tabular}

Table 2. Mechanical properties of the group GIE materials

\begin{tabular}{lccc}
\hline Material & E (GPa) & V & Reference \\
\hline Porcelain (IPS InLine PoM) & 73.19 & 0.4 & Sonelastic \\
Resin cement (Rely X) & 11.54 & 0.24 & Sonelastic \\
Metal coping in Ni-Cr (Vera Bond 11) & 209.20 & 0.24 & Sonelastic \\
Composite resin core (Z250) & 19.16 & 0.54 & Sonelastic \\
Dentin & 18.6 & 0.31 & 17 \\
Periodontal ligament & $6.89 \times 10^{-5}$ & 0.45 & 17 \\
Gutta-percha & $1.4 \times 10^{-1}$ & 0.45 & 18 \\
\hline
\end{tabular}

MN, USA), 3 - metal alloy (Ni-Cr) (Vera Bond II, AalbaDent Inc., Fairfield, CA, USA), and 4 - composite resin (Z250, 3M/ ESPE). After positioning in a specific holder, each sample was submitted to a short impact by a pulsator using mechanical vibration. A transducer captured the acoustic response and translated it into an electric sign in order to read the resonance frequencies. The Young modulus was determined by bending excitation of the sample while the Poisson ratio was obtained by torsion excitation. The steps were repeated for each sample until the last two measurement values became homogeneous, with a difference equal to or less than $2 \%$ from each other.

All materials were assumed as homogeneous, isotropic and linearly elastic; except for the glass fiber post (GFP) (Table 3), which was assumed as orthotropic, homogeneous and linearly elastic (19). GFP was assumed as orthotropic since its mechanical properties are different along the fiber $(\mathrm{x})$ and normal directions ( $\mathrm{y}$ and $\mathrm{z}$ ). Thus, the mechanical characteristics of these materials were represented by the Young modulus in the 3 axes (Ex, Ey, Ez), while Poisson ratio $(v x z, v x z, w z)$ and shearing modulus $(G x z, G x z, G y z)$ in the orthogonal planes (xy, xz and yz) (Table 3) (19). All structures of the models were assumed as perfectly joined, which means no failure at bonding and interposition.

\section{Finite Element Mesh}

The finite element mesh was obtained with the Simpleware 4.1 software using linear tetrahedral elements type C3D4. All models presented 234,824 nodes and $1,243,290$ elements. The mesh refinement was based on convergence analysis of 6\% (20).

\section{Boundary Conditions and Load}

The finite element mesh was transferred to the finite element software (Abaqus 6.10-EF1, Dassault Systèmes Simulus Corp., Providence, RI, USA) to simulate a static occlusal load of $180 \mathrm{~N}$ applied at $45^{\circ}$ on the incisal third of the lingual surface of the canine tooth in all models (13). As boundary condition, the nodes of the periodontal ligament were fixed on the three axes of Cartesian plane $(x, y$ and $z)$, assuming values of $x=y=z=0$ (21).

\section{Results Calculation}

Results were obtained with the finite element software using stress values (hot colors for higher stress and cold colors for lower stress) and numerical analysis. After loading, the maximum von Mises stress (VMS) was calculated. This criterion allows an efficient evaluation of failure pattern and damage occurrence under complex stress $(2,22)$.

\section{Results}

The qualitative analysis of stress values revealed 
difference in von Mises stress distribution between groups GL and GIE (Fig. 1). Higher von Mises stress concentration at the loading area was found for both groups. GIE concentrated more stress in the porcelain and transferred lower stress to the composite resin core than GL. Better von Mises stress distribution was observed in root dentin for


maximum stress for both groups (GL: $1.614 \mathrm{MPa}$ and GIE: $1.975 \mathrm{MPa}$ ). The remaining structures (resin cement, dentin, periodontal ligament, gutta percha and glass fiber post) exhibited similar VMS values and distribution (Table 4).

In quantitative analysis, the porcelain (GL: $5.966 \mathrm{MPa}$ and GIE: $7.478 \mathrm{MPa}$ ), metal coping (GL: $3.811 \mathrm{MPa}$ and GIE: $0.973 \mathrm{MPa}$ ) and composite resin core (GL: $4.771 \mathrm{MPa}$ and GIE: $0.026 \mathrm{MPa}$ ) showed the highest differences in von Mises stress values (Fig. 1) between the groups of study.

\section{Discussion}

The present study evaluated the reliability of FEA on the results of different mechanical properties ( $E$ and $v$ ) of materials, using literature data and the impulse excitation technique. The work hypothesis was rejected since the stress values showed that different Young modulus and Poisson ratio changed von Mises stress distribution and value (Table 4).

In the present work the groups $\mathrm{GL}$ and $\mathrm{GIE}$ used the same dental materials, but they showed different mechanical properties. This difference in mechanical properties of the materials ( $E$ and $v$ ) showed that materials with higher

Table 3. Orthotropic mechanical properties of the glass fiber post

\begin{tabular}{lccc}
\hline $\mathrm{E}(\mathrm{GPa})$ & $v$ & Shear modulus $(\mathrm{GPa})$ & Reference \\
\hline $\mathrm{X}=37$ & $\mathrm{X} y=0.27$ & $\mathrm{Gxy}=3.1$ & \\
$\mathrm{Y}=9.5$ & $\mathrm{Xz}=0.34$ & $\mathrm{Gxz}=3.5$ & 19 \\
$\mathrm{Z}=9.5$ & $\mathrm{Yz}=0.27$ & $\mathrm{Gyz}=3.1$ & \\
\hline
\end{tabular}

Table 4. von Mises stress values (VMS) of the groups

\begin{tabular}{lcc}
\hline Structures & $\mathrm{GL}$ & $\mathrm{GlE}$ \\
\hline Porcelain & 5.966 & 7.478 \\
Cement & 0.605 & 0.605 \\
Metal coping & 3.811 & 0.973 \\
Composite resin core & 4.771 & 0.026 \\
Root dentin & 1.614 & 1.975 \\
Periodontal ligament & 0.089 & 0.077 \\
Gutta-percha & 0.011 & 0.013 \\
Glass fiber post & 0.447 & 0.513 \\
\hline
\end{tabular}

Young modulus absorb higher stress; which agrees with literature $(2,23)$. It was found that the von Mises stress value of GIE porcelain was 1.253 times higher than GL and VMS of the GL metal coping was 3.917 times higher than GIE. Thus, comparing the results between the groups, it may be assumed that the GIE porcelain is more protective than GL since it avoided stress concentration on fragile structures like the composite resin core (GL: $4.771 \mathrm{MPa}$ and GIE: 0.026 $\mathrm{MPa}$ ). Considering the individual results of the groups, it may be suggested that the risk of core fracture in GL was 183.5 times higher than in GIE (Table 5).

The FEA reliability depends on using an appropriate software to solve the mathematical problem, the structures geometry, material properties, quality of finite element mesh, boundary and loading conditions $(4,24)$. Over the
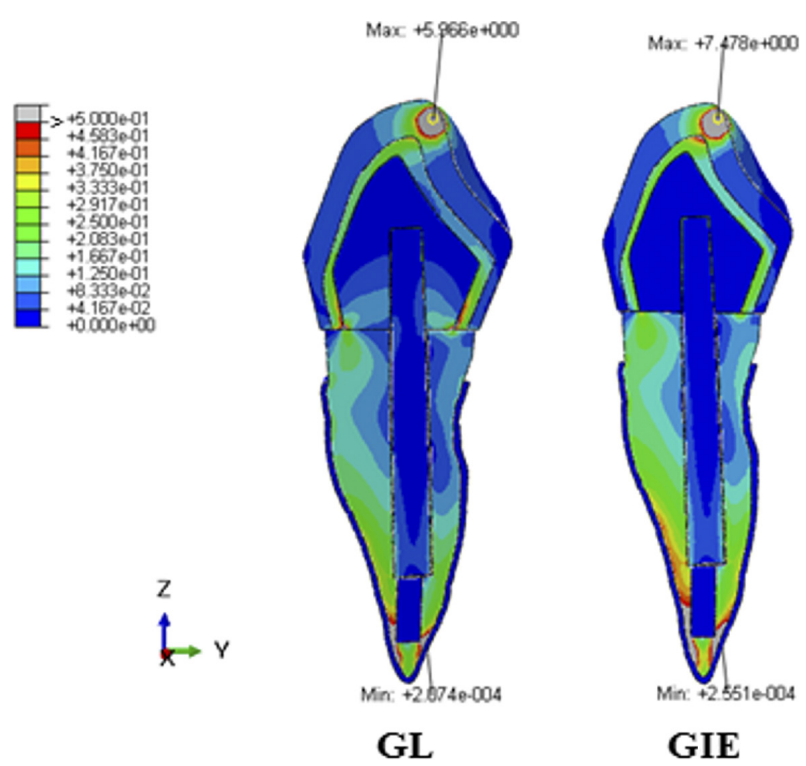

Figure 1. von Mises stress (VMS) distribution in the canine restored with a glass fiber post.

Table 5. Ratio between the von Mises stress values (VMS) of the groups

\begin{tabular}{lcc}
\hline \multirow{2}{*}{ Structures } & \multicolumn{2}{c}{ VMS Ratio } \\
\cline { 2 - 3 } & $\mathrm{GL} / \mathrm{GlE}$ & $\mathrm{GlE} / \mathrm{GL}$ \\
\hline Porcelain & 0.797 & 1.253 \\
Cement & 1 & 1 \\
Metal coping & 3.917 & 0.255 \\
Composite resin core & 185.5 & 0,005 \\
Root dentin & 0.817 & 1.22 \\
Periodontal ligament & 0.11 & 0.865 \\
Gutta-percha & 0.846 & 1.181 \\
Glass fiber post & 0.871 & 1.148 \\
\hline
\end{tabular}


years, there was a wide range of commercial brands and mechanical properties for the same dental material in order to provide longevity, stability and better clinical performance. Thus, it is expected that the materials' properties used at the beginning of this century be different from currently used dental materials. Therefore, the authors suggest that it is important to determine the mechanical properties of materials used in the study to be able to extrapolate the results to a clinical situation.

It is important to highlight that the present research does not intend to criticize the previous FEA studies but enlighten the scientific community about the relevance of determining the Young modulus and Poisson ratio for each new dental material in order to avoid inaccurate analyses and false results. Finally, the findings of this study indicate that the definition of mechanical properties ( $E$ and $v$ ) of materials is essential for the FEA results reliability.

\section{Resumo}

0 presente estudo avaliou a confiabilidade do MEF nos resultados de diferentes propriedades mecânicas (E e v) dos materiais. Dois modelos 3D de um canino superior com tratamento endodôntico, pino intrarradicular, núcleo em resina composta e restaurado com coroa metalocerâmica foram gerados de acordo com imagens de micro-CT. Dois grupos com diferentes valores de E e v para a cerâmica, coping metálico, cimento resinoso e resina composta foram criados. As propriedades dos materiais para o grupo GL foram baseadas em dados obtidos da literatura, enquanto para o grupo GIE a técnica de excitação por impulso foi utilizada. Carga de $180 \mathrm{~N}$ foi aplicada a $45^{\circ}$ na superfície lingual do terço incisal do canino. Todos os modelos foram suportados pelo ligamento periodontal $(x=y=z=0)$. Tensões equivalentes de von Mises (VMS) foram calculadas. Os valores de tensões revelaram diferença entre os grupos, ambos para a distribuição e valor das VMS. A cerâmica (GL: 5,966 MPa; GIE: 7,478 MPa), coping metálico (GL: 3,811 MPa; GIE: 0,973 MPa) e núcleo (GL: 4,771 MPa; GIE: 0,026 MPa) foram significativamente afetados. Em conclusão, este estudo mostrou que a determinação das propriedades mecânicas ( $E$ and $v$ ) dos materiais é essencial para a confiabilidade dos resultados do MEF.

\section{Acknowledgements}

The authors wish to thank the support by FAPESP (Grant \# 2013/23905-9), Laboratory of Biomechanical Studies in Prosthodontics and Implants at the Department of Dental Materials and Prosthodontics, and the Endodontics Research Laboratory at the Department of Restorative Dentistry, School of Dentistry of Ribeirão Preto, University of São Paulo, Brazil.

\section{References}

1. Santos-Filho PC, Veríssimo C, Soares PV, Saltarelo RC, Soares CJ, Marcondes Martins LR. Influence of ferrule, post system, and length on biomechanical behavior of endodontically treated anterior teeth. J Endod 2014;40:119-123.

2. Veríssimo C, Simamoto Júnior PC, Soares CJ, Noritomi PY, Santos-Filho PC. Effect of the crown, post, and remaining coronal dentin on the biomechanical behavior of endodontically treated maxillary central incisors. J Prosthet Dent 2014;111:234-246.

3. Vafaee $F$, Khoshhal M, Rezaei A, Sooltani F, Jalalzadeh M, Yalpaniyan A, et al.. Multiple in vitro analyses of fracture resistance in maxillary central incisors restored with fiber posts. Iran Endod J 2010;5:125-130.

4. Tajima K, Chen KK, Takahashi N, Noda N, Nagamatsu Y, Kakigawa H. Three-dimensional finite element modeling from CT images of tooth and its validation. Dent Mater J 2009;28:219-226.
5. Ausiello P, Apicella A, Davidson CL. Effect of adhesive layer properties on stress distribution in composite restorations - a 3D finite element analysis. Dent Mater 2002;18:295-303

6. Aggarwal S, Garg V. Finite element analysis of stress concentration in three popular brands of fiber posts systems used for maxillary central incisor teeth. J Conserv Dent 2011;14:293-296.

7. Oliveira JS, Chaves CAL, Silva-Sousa YTC, Gomes EA. The finite element methods on oral rehabilitation: new trend for endodontically treated teeth. Braz Dent Sci 2014;17:12-19.

8. Murakami N, Wakabayashi N. Finite element contact analysis as a critical technique in dental biomechanics: a review. J Prosthodont Res 2014;58:92-101.

9. Della Bona A, Borba M, Benetti P, Duan Y, Griggs JA. Three-dimensional finite element modelling of all-ceramic restorations based on micro-CT. J Dent 2013;41:412-419.

10. Borba M, de Araújo MD, de Lima E, Yoshimura HN, Cesar PF, Griggs JA, et al.. Flexural strength and failure modes of layered ceramic structures. Dent Mater 2011;27:1259-1266.

11. Passos SP, Kimpara ET, Bottino MA, Rizkalla AS, Santos GC Jr. Effect of ceramic thickness and shade on mechanical properties of a resin luting agent. J Prosthodont 2014;23:462-466.

12. Eraslan 0, Aykent $F$, Yucel MT, Akman $S$. The finite element analysis of the effect of ferrule height on stress distribution at post-and-core-restored all-ceramic anterior crowns. Clin Oral Investig 2009;13:223-227.

13. Gomes ÉA, Gueleri DB, da Silva SR, Ribeiro RF, Silva-Sousa YT. Threedimensional finite element analysis of endodontically treated teeth with weakened radicular walls restored with different protocols. J Prosthet Dent 2015;114:383-389.

14. Akkayan B. An in vitro study evaluating the effect of ferrule length on fracture resistance of endodontically-treated teeth restored with fiberreinforced and zirconia dowel systems. J Prosthet Dent 2004;92:155-162.

15. Silva NR, Bonfante E, Rafferty BT, Zavanelli RA, Martins LL, Rekow ED, et al.. Conventional and modified veneered zirconia vs. metalloceramic: fatigue and finite element analysis. J Prosthodont 2012;21:433-439.

16. Asmussen $E_{1}$ Peutzfeld $A$, Sahafi A. Finite element analysis of stresses in endodontically treated, dowel-restored teeth. J Prosthet Dent 2005;94:321-329.

17. Reinhardt RA, Krejci RF, Pao YC, Stannard JG. Dentin stresses in post-reconstructed teeth with diminishing bone support. J Dent Res 1983;62:1002-1008.

18. Friedman CM, Sandrik JL, Heuer MA, Rapp GW. Composition and mechanical properties of gutta-percha endodontic points. J Dent Res. 1975;54:921-925.

19. Lanza A, Aversa R, Rengo S, Apicella D, Apicella A. 3D FEA of cemented steel, glass and carbon posts in a maxillary incisor. Dent Mater 2005;21:709-715.

20. Pessoa RS, Vaz LG, Marcantonio E Jr, Vander Sloten J, Duyck J, Jaecques SV. Biomechanical evaluation of platform switching in different implant protocols: computed tomography-based three-dimensional finite element analysis. Int J Oral Maxillofac Implants 2010;25:911-919.

21. Rocha EP, Anchieta RB, Freitas AC Jr, de Almeida EO, Cattaneo PM, Chang Ko C. Mechanical behavior of ceramic veneer in zirconiabased restorations: a 3-dimensional finite element analysis using microcomputed tomography data. J Prosthet Dent 2011;105:14-20.

22. Dejak B, Młotkowski A. Finite element analysis of strength and adhesion of cast posts compared to glass fiber-reinforced composite resin posts in anterior teeth. J Prosthet Dent 2011;105:115-126.

23. Okamoto K, Ino T, Iwase N, Shimizu E, Suzuki M, Satoh G, et al.. Threedimensional finite element analysis of stress distribution in composite resin cores with fiber posts of varying diameters. Dent Mater J 2008;27:49-55.

24. Marghalani TY, Hamed MT, Awad MA, Naguib GH, Elragi AF. Threedimension finite element analysis of custom made ceramic dowel made using CAD/CAM technology. J Prosthodont 2012;21:440-450. 